\title{
Arsenic Trioxide in Synergy with Vitamin D Rescues the Defective VDR-PPAR- $\gamma$ Functional Module of Autophagy in Rheumatoid Arthritis
}

\author{
Weiyan Wang, ${ }^{1}$ Chunling Li $\mathbb{D},{ }^{1}$ Zhiyi Zhang $\mathbb{D}{ }^{1}$ and Yue Zhang $\mathbb{D}^{1,2}$ \\ ${ }^{1}$ Department of Rheumatology, The First Affiliated Hospital of Harbin Medical University, 23 Youzheng St., Nangang District, \\ Harbin, China \\ ${ }^{2}$ Shenzhen Futian Hospital for Rheumatic Diseases, 22 Nonglin Road, Shenzhen, China
}

Correspondence should be addressed to Zhiyi Zhang; zhangzhiyi2014@163.com and Yue Zhang; toronto101@163.com

Received 20 November 2018; Revised 17 March 2019; Accepted 1 April 2019; Published 7 May 2019

Academic Editor: Antonio Brunetti

Copyright (C) 2019 Weiyan Wang et al. This is an open access article distributed under the Creative Commons Attribution License, which permits unrestricted use, distribution, and reproduction in any medium, provided the original work is properly cited.

Dysregulated autophagy leads to autoimmune diseases including rheumatoid arthritis (RA). Arsenic trioxide (ATO) is a single agent used for the treatment of acute promyelocytic leukemia and is highly promising for other malignancies but is also attractive for RA, although its relationship with autophagy remains to be further clarified and its application optimized. For the first time, we report a defective functional module of autophagy comprising the Vitamin D receptor (VDR), PPAR- $\gamma$, microtubule-associated protein 1 light-chain 3 (LC3), and p62 which appears in RA synovial fibroblasts. ATO alleviated RA symptoms by boosting effective autophagic flux through significantly downregulating p62, the inflammation and catabolism protein. Importantly, low-dose ATO synergizes with Vitamin D in RA treatment.

\section{Introduction}

Rheumatoid arthritis (RA) is a chronic inflammatory joint disease that leads to cartilage and bone damage as well as disability [1].

Autophagy is defined as a degradation mechanism by which cells recycle cytoplasmic components. Several autophagy-related genes are involved including Beclin1, microtubule-associated protein 1 light-chain 3 (LC-3), p62, and mammalian target of rapamycin (mTOR) [2-4]. The assessment of autophagic activity can be achieved by detection of the LC-3 protein. Autophagic flux is a complex process that involves transporting, binding, degrading, and recycling the cytoplasmic components. Nevertheless, increases in the levels of LC-3 can be caused by either the induction of autophagy or inhibited fusion of the autophagosomes with lysosomes; it cannot be used to monitor autophagic flux per se. The p62 protein serves as a link between LC-3 and ubiquitinated substrates and is degraded in autolysosomes. Thus, inhibition of the final step of autophagy correlates with increased levels of p62 and indicates impaired flux [5]. Dysregulated autophagic flux is involved in the pathogenesis of many autoimmune diseases, including RA, by regulating the organism's lifespan and cartilage homeostasis [6-9]. In addition, the activation of autophagy in immune cells is significantly associated with inflammatory parameters such as interleukin-6 (IL-6) and tumor necrosis factor- $\alpha$ (TNF- $\alpha$ ), which are proinflammatory cytokines involved in the pathogenesis and progression of RA [10].

The Vitamin D receptor (VDR) is expressed in multiple cells and numerous RA and autophagy-related genes, including mTOR, are potential candidate targets of Vitamin D (Vit D) and VDR [11, 12]. It maintains "robustness" in unfavorable conditions and serves a "capacitor" in homeostasis in RA biology $[13,14]$. Peroxisome proliferator-activated receptor$\gamma($ PPAR $-\gamma)$ is a primary target of Vit D [15]. In addition, both VDR and PPAR- $\gamma$ are key autophagy regulators $[16,17]$ and play central roles in the development and progression of RA, supporting the possible involvement of autophagy in RA. In vivo and in vitro experiments confirmed that the PPAR- $\gamma$ agonist could downregulate inflammatory cytokines $[18,19]$. 
TABLE 1: Sequences of primers.

\begin{tabular}{lrc}
\hline Target gene & Forward primer $\left(5^{\prime}-3^{\prime}\right)$ & Reverse primer $\left(5^{\prime}-3^{\prime}\right)$ \\
\hline GAPDH & GCACCGTCAAGGCTGAGAAC & TGGTGAAGACGCCAGTGGA \\
$P P A R-\gamma$ & TGGAATTAGATGACAGCGACTTGG & CTGGAGCAGCTTGGCAAACA \\
$V D R$ & ACTCACCTCTGCCTCAATGTGAA & GATGAGGCAACAGCATTATCCAAG \\
$L C 3$ & CTTCTGAGCCAGCAGTAGGG & GGCAGAGTAGGTGGGTTGGT \\
$P 62$ & ACATAGCTTGCCTAATGGCTTTCAC \\
$m T O R$ & GGCCTGGATGGCAACTACAGA & CCTGCCTGCTGACAACACCTA \\
\end{tabular}

Bone erosion can be alleviated in RA patients by reducing catabolism through PPAR- $\gamma$ pathway activation [20]. The regulatory effects of VDR and PPAR $\gamma$ through autophagy have been proven in tumors and other diseases [21-23]. Nevertheless, the exact role and involvement of VDR and PPAR- $\gamma$ in RA-related autophagy remain to be defined.

The search for novel drugs that can manage more than one single age-related disease is encouraged [24]. Among these drugs, arsenic trioxide $\left(\mathrm{As}_{2} \mathrm{O}_{3}, \mathrm{ATO}\right)$ is recognized for treating tumors $[25,26]$ and autoimmune rheumatic diseases by enhancing apoptosis and inhibiting angiogenesis [27-29]. ATO has been shown to induce antitumor effects through autophagy [30]. However, the effect of ATO on autophagy in $\mathrm{RA}$ is unknown.

In the present study, we demonstrated for the first time that VDR, PPAR- $\gamma$, and LC-3 participate in a functional module of autophagy (a functional module is a group of genes that are tightly associated through multiple feedback loops) and are significantly upregulated in RA synovial tissues, although autophagic flux was unexpectedly severely impaired. Surprisingly, ATO rescued this defective functional module of autophagy in RA fibroblast-like synoviocytes (FLS) and mice with RA, and the effect was even better when ATO was used with Vit D. Hence, ATO combined with Vit D could be a potential therapeutic strategy against RA.

\section{Materials and Methods}

2.1. Synovial Fibroblast Culture and TNF- $\alpha$ Stimulation. RA FLS and normal human (NH) FLS were purchased from Cell Applications (San Diego, CA, USA) and maintained in a synoviocyte growth medium (Cell Applications). Cells were used for the experiments in stages 4-6. RA FLS were pretreated with $50 \mathrm{ng} / \mathrm{mL}$ of TNF- $\alpha$ for $4 \mathrm{~h}$ before the application of ATO and/or Vit D. Cell culture supernatants were used for enzyme-linked immunosorbent assays (ELISAs) $48 \mathrm{~h}$ after the addition of the treatments.

2.2. In Vitro Proliferation Assay. Cell proliferation was evaluated with a Cell Counting Kit-8 (Sigma, St Louis, MO, USA) following procedures described earlier with minor modifications [31]. Briefly, $10^{4}$ cells were seeded in a 96-well plate. After $24 \mathrm{~h}$, different concentrations of drugs or vehicles were added with fresh medium. Cells were incubated at $37^{\circ} \mathrm{C}$ for $48 \mathrm{~h}$. The plates were read at $450 \mathrm{~nm}$. The experiments were repeated three times.
2.3. RNA Preparation and Real-Time Quantitative Polymerase Chain Reaction Analysis. Total RNA was extracted from FLS with TRIzol reagent (Invitrogen, Carlsbad, CA, USA) and converted to cDNA. Real-time quantitative polymerase chain reaction (PCR) amplification was performed as described previously [28]. The sequences of the primers are shown in Table 1. GAPDH was used as an internal control. All samples were measured in triplicate and the results were evaluated via the $2^{-\Delta \Delta \text { ct }}$ method [9].

2.4. Western Blotting. Equal amounts of proteins were obtained and separated by SDS-PAGE and transferred to a polyvinylidene fluoride membrane as described previously [28]. Specific primary antibodies were added, including anti-PPAR- $\gamma$ (catalog no. ab41928, Abcam, Cambridge, MA, USA), anti-VDR (catalog no. 12550, Cell Signaling, Cambridge, MA, USA), anti-LC-3-I/II (catalog no. 12741, Cell Signaling), anti-p62 (catalog no. ab56416, Abcam), antimTOR (catalog no. ab32028, Abcam), and anti-p-mTOR (catalog no. ab109268, Abcam). The reactive bands were visualized with a chemiluminescence detection system and analyzed with ImageJ software (National Institutes of Health, USA).

2.5. RNA Interference. VDR knockdown was achieved by transfecting specific VDR small interfering RNA (siRNA) into RA FLS. The siRNA sequence was as follows: forward, $5^{\prime}$-GCUGAAGUCAAGUGCCAUUTT- $3^{\prime}$; reverse, $5^{\prime}$ AAUGGCACUUGACUUCAGCTT- $3^{\prime}$. RA FLS were plated in 12 -well plates at $10^{5}$ cells per well with serum-free DMEM and transfected with siRNA via Lipofectamine 2000 (Invitrogen) as previously described [28]. Six hours after transfection, the culture medium was replaced by DMEM with 10\% FBS. Knockdown efficiency was determined by real-time PCR and western blot analysis. The experiments were repeated at least three times.

2.6. Establishment of Collagen-Induced Arthritis. Specific pathogen-free 6-week-old male DBA/1J mice weighing $18 \pm 2 \mathrm{~g}$ were purchased from SLAC (Shanghai, China). Animal welfare and experimental procedures were carried out in accordance with the Guide for the Care and Use of Laboratory Animals and were approved by the Institutional Animal Care and Use Committee of Harbin Medical University. The collagen-induced arthritis (CIA) mouse model was established as described previously [28]. Mice were randomly 
assigned to different groups ( $n=6$ per group): normal control group (mice without immunization and injected with saline); the CIA control group (CIA mice treated with saline, CIAsaline); the ATO-treated group (CIA mice treated with ATO at a dose of 1.0 or $2.0 \mathrm{mg} / \mathrm{kg} /$ day $)$, Vit D $(400 \mathrm{ng} / \mathrm{kg} / \mathrm{d})$ or Vit D $(400 \mathrm{ng} / \mathrm{kg} / \mathrm{d})+$ ATO $(2.0 \mathrm{mg} / \mathrm{kg} / \mathrm{day})$; and the methotrexate (MTX) group (CIA mice treated with MTX at $2 \mathrm{mg} / \mathrm{kg} /$ week as a positive control). Mice were given intraperitoneal injections from day 28 to day 41 . The body weight of each mouse was recorded every other day from day 21.

2.7. Assessment of Arthritis Severity. To evaluate the severity of the arthritis quantitatively, the arthritis score was assessed every 2 days starting from day 21 , according to a scoring system used previously [32]. In addition, body weight and the thickness of the two hind paws were measured every other day.

2.8. Microcomputed Tomography Imaging. To investigate the effects of ATO on the three-dimensional (3D) bone structure, we conducted an assay using microcomputed tomography (micro-CT) imaging (Quantum GX, Perkin Elmer, Waltham, USA). Mice were scanned and reconstructed into a $3 \mathrm{D}$ structure via micro-CT imaging 39 days after the initial collagen injection. The voxel size was $72 \mu \mathrm{m}$, the X-ray tube voltage was $90 \mathrm{KV}$, the current was $88 \mu \mathrm{A}$, and the exposure time was $4 \mathrm{~min}$. Mean CT values of the hind paws were calculated with Caliper Analyze software (Analyze Direct, Kansas, USA) to assess bone loss.

2.9. Histological Analysis. Whole knee joints of the mice were collected and fixed in $10 \%$ buffered neutral formalin and decalcified in $10 \%$ EDTA for 4 weeks. The paraffin-embedded specimens were stained with hematoxylin and eosin (H\&E). Histological changes were scored in a blinded manner by two independent observers based on synovial hyperplasia, joint inflammation, and bone erosion following a scoring system described previously $[33,34]$.

2.10. Immunohistochemistry Analysis. Immunohistochemistry was performed with specific antibodies for target proteins following a protocol described previously with some modifications [6]. Knee joint sections on slides were incubated with anti-VDR, anti-PPAR- $\gamma$, anti-LC-3, or antiP62 (Boster, Wuhan, China) antibodies. Subsequently, the sections were stained with a polymer horseradish peroxidase (HRP) detection system (PV9001, ZSGB-BIO, Beijing, China) and visualized with a diaminobenzidine (DAB) peroxidase substrate kit (ZLI-9017, ZSGB-BIO, Beijing, China). Each section was evaluated under a microscope (DMi8, LEICA, Wetzlar, Germany) in three randomly selected areas at a magnification of $20 \times$. Image-Pro Plus 6 (Media Cybernetics, Inc.) was used to analyze the average integrated optical density (IOD) according to a previously described protocol [35].

2.11. Enzyme-Linked Immunosorbent Assay. Serum samples from the mice and the cell culture supernatant were collected and stored at $-80^{\circ} \mathrm{C}$. The concentrations of IL- 6 , IL- $1 \beta$, matrix metalloproteinase-3 (MMP-3) and MMP-13 were detected with commercial kits (Elabscience Biotechnology Co., Ltd., Wuhan, China), according to the manufacturer's protocols. All assays were conducted in triplicate.

2.12. Statistical Analysis. Data are represented as means \pm standard error of the mean and were analyzed via Student's $t$-test or analysis of variance (ANOVA), as appropriate. All analyses were carried out in SPSS 17.0 software. Values of $p<$ 0.05 were considered statistically significant.

\section{Results}

3.1. ATO Rescues the Defective VDR-PPAR- $\gamma$ Functional Module of Autophagy Both In Vivo and In Vitro. Regarding potential side effects and safety, we examined the influence of ATO and Vit D on the proliferation of RA FLS. Although the optical density value decreased, different concentrations of ATO and Vit D showed no significant influence on cell proliferation (Figure 1(a)). RA FLS were detected after treatment with different doses of ATO $(0.1,0.5,1.0,2.0$, and $4.0 \mu \mathrm{M})$. VDR, PPAR- $\gamma$, and LC-3 were significantly upregulated after ATO treatment, with the peak effect seen at $2 \mu \mathrm{M}$; importantly, p62 was surprisingly significantly downregulated (Figure 2(a), $p<0.05$ ). Whether or not RA FLS exhibited defective autophagic flux was investigated by using VDR, PPAR- $\gamma$, LC-3, and p62 mRNA and protein in normal human (NH) FLS and RA FLS. The expression levels of VDR, PPAR- $\gamma$, and LC-3 were significantly upregulated in RA FLS compared with normal human FLS. Meanwhile, p62 mRNA and protein were also higher in RA FLS, which may indicate blockage of autophagy (Figure 1(b), $p<0.05$ ).

Afterwards, RA FLS were treated with ATO $(2 \mu \mathrm{M})$ after VDR knockdown. PPAR- $\gamma$ and LC-3 were significantly downregulated but p62 was enhanced after silencing VDR, and ATO could reverse these effects (Figure 1(c), $p<0.05$ ). Immunohistochemistry was performed to validate the effect of ATO on the VDR-PPAR- $\gamma$ autophagy functional module in CIA mice. Strikingly, treatment with ATO $(2 \mathrm{mg} / \mathrm{kg} / \mathrm{d})$ or MTX (2 mg/kg/week) led to significant increases in the expression of VDR, PPAR- $\gamma$, and LC-3 and a decrease in p62 compared with CIA-saline mice (Figure 2(b), $p<0.05$ ). Thus, ATO alone may activate the VDR-PPAR- $\gamma$ autophagy functional module both in vitro and in vivo.

3.2. Combined Effect of ATO and Vit D on the VDR-PPAR$\gamma$ Functional Module of Autophagy. Both ATO and Vit D upregulated the expression of VDR, PPAR- $\gamma$, and LC-3 in vitro (Figure $3(\mathrm{a}), p<0.05)$, but ATO had a synergistic effect with Vit D on this upregulation in RA FLS (Figure 3(a), $p<0.05)$; low doses of ATO $(1 \mathrm{mg} / \mathrm{kg} / \mathrm{d})$ plus Vit D $(400 \mathrm{ng} / \mathrm{kg} / \mathrm{d})$ achieved similar effects to ATO $(2 \mathrm{mg} / \mathrm{kg} / \mathrm{d})$ (Figures 3(a) and 4(b)). Furthermore, ATO synergized with Vit D in vivo to upregulate the expression of VDR, PPAR- $\gamma$, and LC-3 significantly and downregulate p62 in the synovium of mice (Figure 2(b), $p<0.05$ ). Therefore, we consider that 

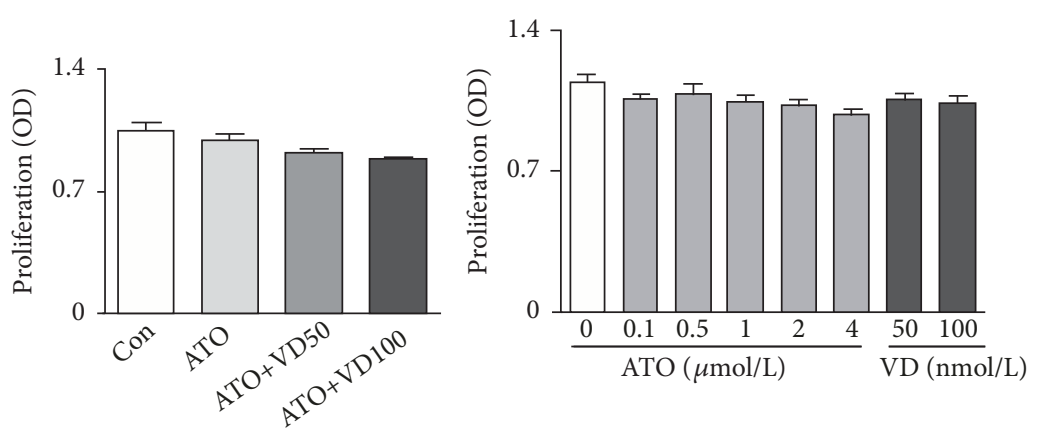

(a)

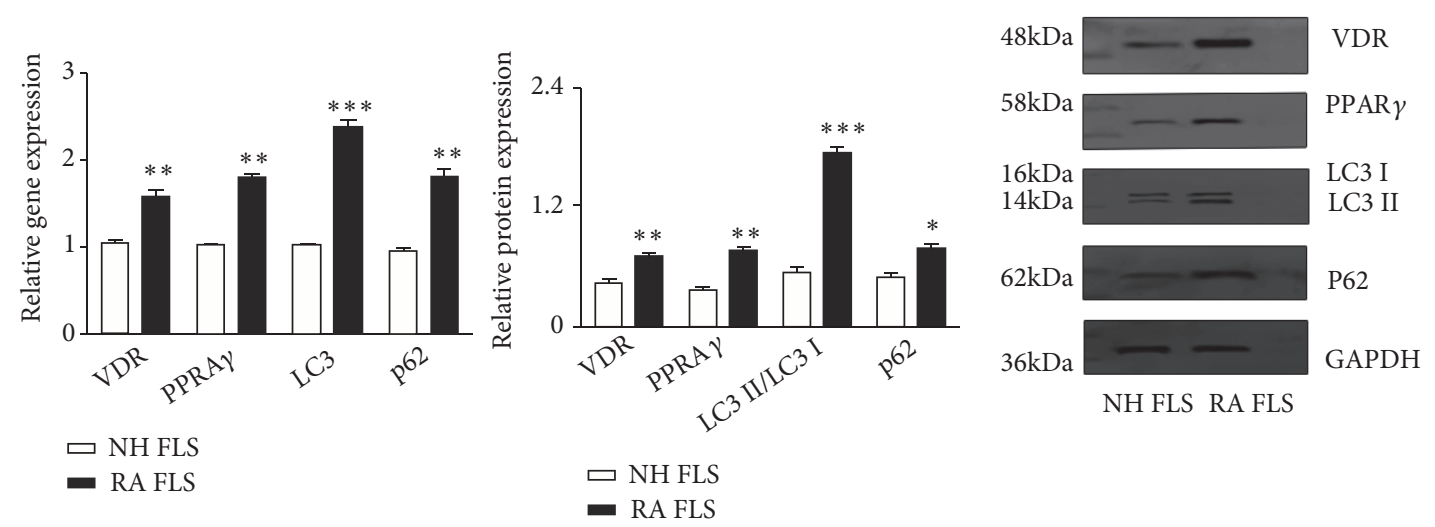

(b)
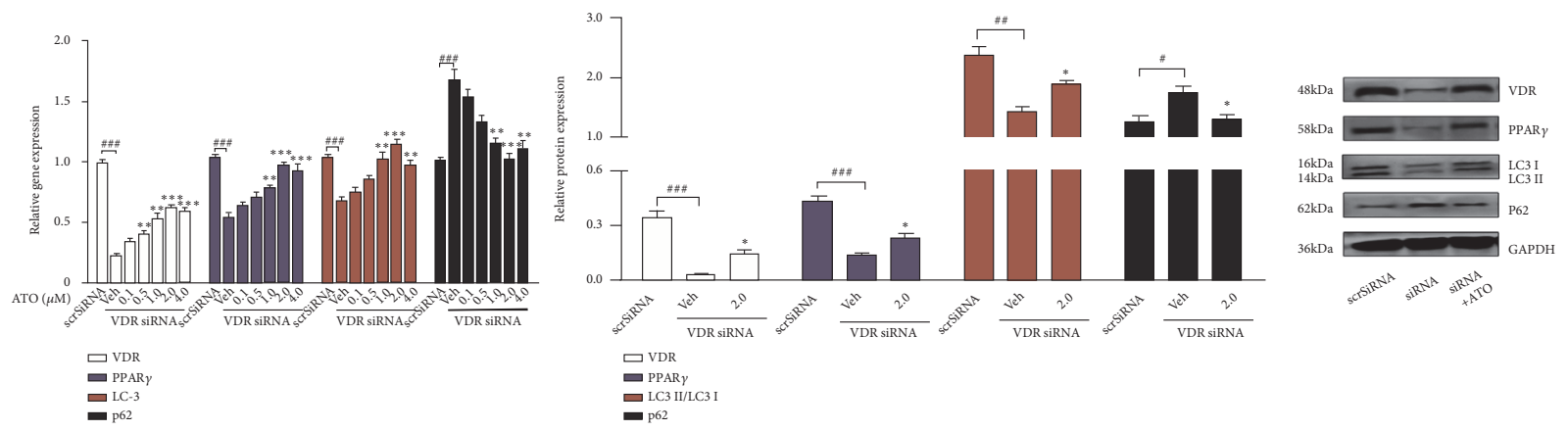

(c)

FIGURE 1: (a) After treatment with different concentrations of arsenic trioxide (ATO) $(0.1,0.5,1.0,2.0$, or $4.0 \mu \mathrm{M})$ or Vitamin D (Vit D) (50 or $100 \mathrm{nM}$ ) for $48 \mathrm{~h}(n=3)$, CCK-8 was added to rheumatoid arthritis (RA) fibroblast-like synoviocytes (FLS) and incubated for $1 \mathrm{~h}$. Absorbance (optical density value) at $450 \mathrm{~nm}$ was detected by a microplate reader. The results showed no significant influence on cell proliferation after the administration of different concentrations of ATO and Vit D. The results are presented as the mean \pm SEM. (b) Real-time PCR and western blot analysis showed significantly increased expression of the Vitamin D receptor (VDR), PPAR- $\gamma$, LC-3, and p62 in RA FLS ( $n=3$ ) compared with normal human (NH) FLS $(n=3 ; * p<0.05, * * p<0.01, * * * p<0.001)$. The results are presented as means \pm SEM. (c) Silencing of VDR in RA FLS significantly reduced the expression of VDR, PPAR- $\gamma$, and LC- 3 but induced the expression of p62. Addition of ATO could reverse the effect of small interfering RNA (siRNA) ( $n=3, \# p<0.05 \# \# p<0.01 \# \# \# p<0.001$ versus scrambled siRNA-treated cells (SCR-siRNA); $* p<0.05$; $* * p<0.01 * * * p<0.001$ versus vehicle). Vehicle $=$ RA FLS treated with the medium alone after silencing by VDR siRNA.

ATO may have a synergistic effect with Vit D on the VDRPPAR- $\gamma$ autophagy functional module in vivo and in vitro.

\subsection{ATO Alleviates Symptoms and Joint Destruction in CIA} Mice. We assessed the body weight, degree of paw swelling, and arthritis scores of the CIA and control mice. Both ATO (1 or $2 \mathrm{mg} / \mathrm{kg} / \mathrm{d})$ and Vit D (400 ng/ $/ \mathrm{kg} / \mathrm{d})$ alone alleviated the symptoms of CIA mice (Figure 5(c), $p<0.01$ ). However, combining ATO and Vit D further reduced the arthritis score but this was not significantly different from ATO alone. The severity of arthritis in CIA mice was assessed by H\&E staining of knee joint sections. ATO treatment at $2 \mathrm{mg} / \mathrm{kg} / \mathrm{d}$ and Vit D (400 ng/kg/d) significantly reduced the histological scores including synovial hyperplasia, cartilage, and bone erosion and joint inflammatory (Figure $5(\mathrm{~b}), n=6, p<0.01$ ). Additionally, ATO $(2 \mathrm{mg} / \mathrm{kg} / \mathrm{d})$ significantly enhanced the 

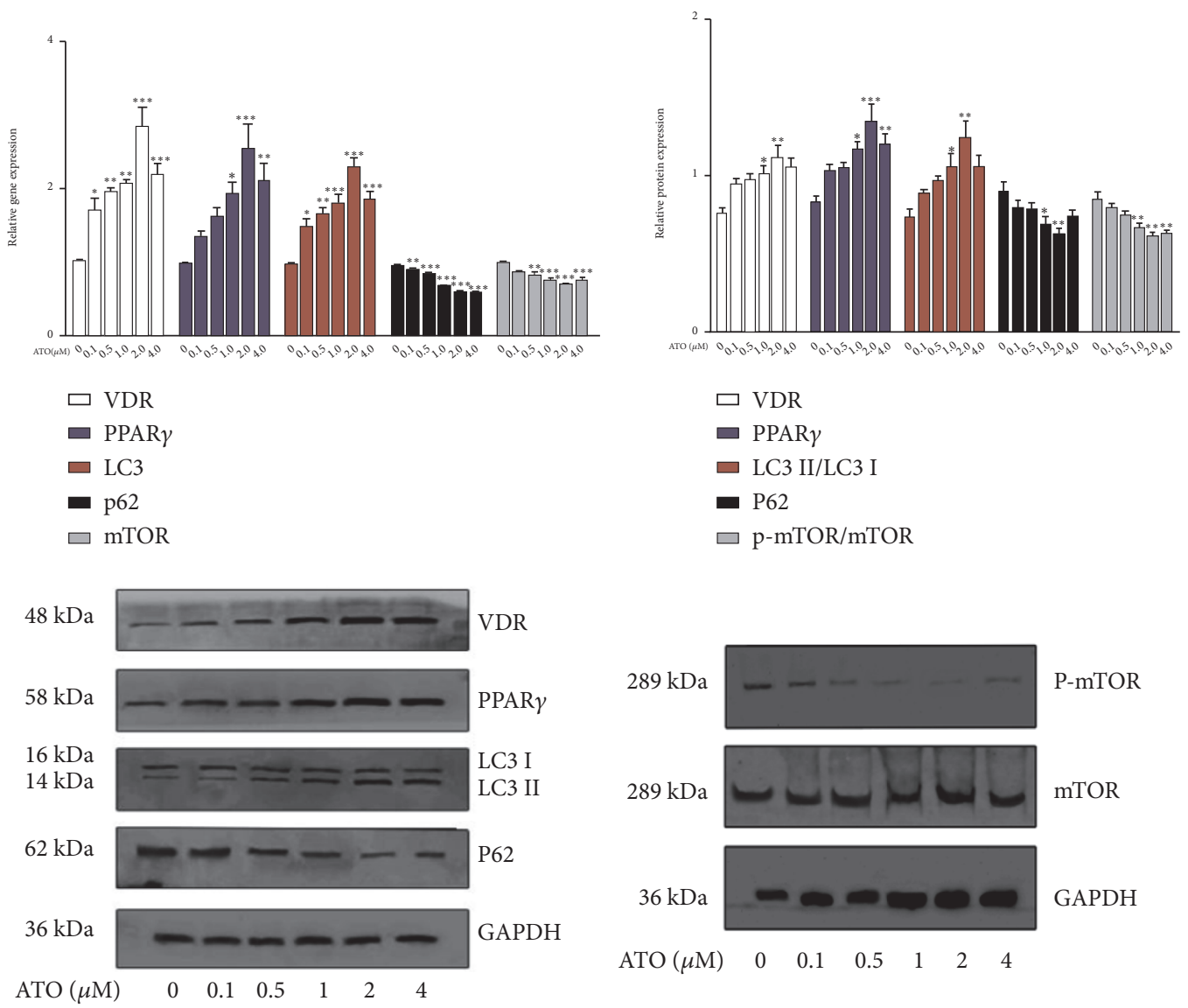

(a)
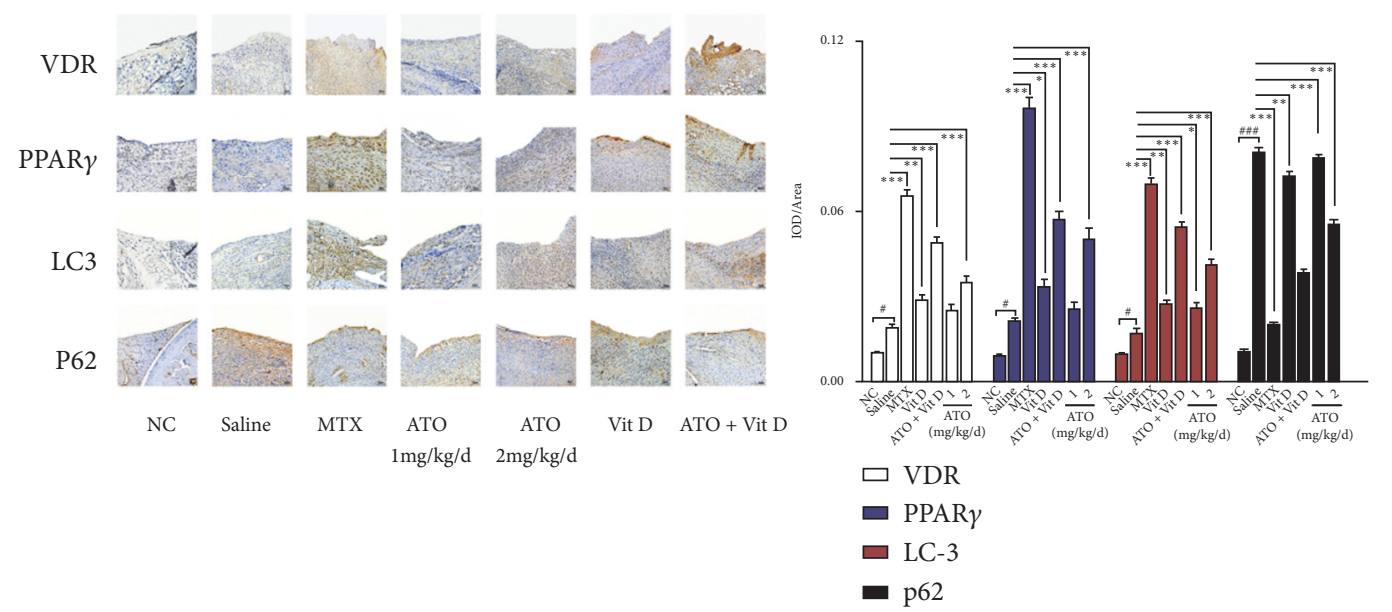

(b)

Figure 2: Arsenic trioxide (ATO) and Vitamin D rescue the defective Vitamin D receptor (VDR)-PPAR- $\gamma$ autophagy functional module in rheumatoid arthritis (RA). (a) Increased expression levels of PPAR- $\gamma$, VDR, and LC-3 and decreased expression levels of p62 after ATO administration in RA fibroblast-like synoviocytes (FLS) $(n=3 ; * p<0.05 ; * * p<0.01)$. Data are expressed as means \pm standard error of the mean (SEM). (b) Increased average integrated optical density (IOD) values for VDR, PPAR- $\gamma$, LC-3, and p62 in synovial tissue in collagen-induced arthritis- (CIA-) saline mice (saline) compared with normal controls (NC). CIA mice under ATO and methotrexate (MTX) treatments showed additional increased average IOD values for VDR, PPAR- $\gamma$, and LC- 3 but decreased p62 in synovial tissue compared with the saline group $(n=6 ; * p<0.05 ; * * p<0.01 ; * * * p<0.001$, experiment versus saline). Magnification $=20 \times$. Bars $=50 \mu \mathrm{m}$. Data are expressed as means \pm SEM. 

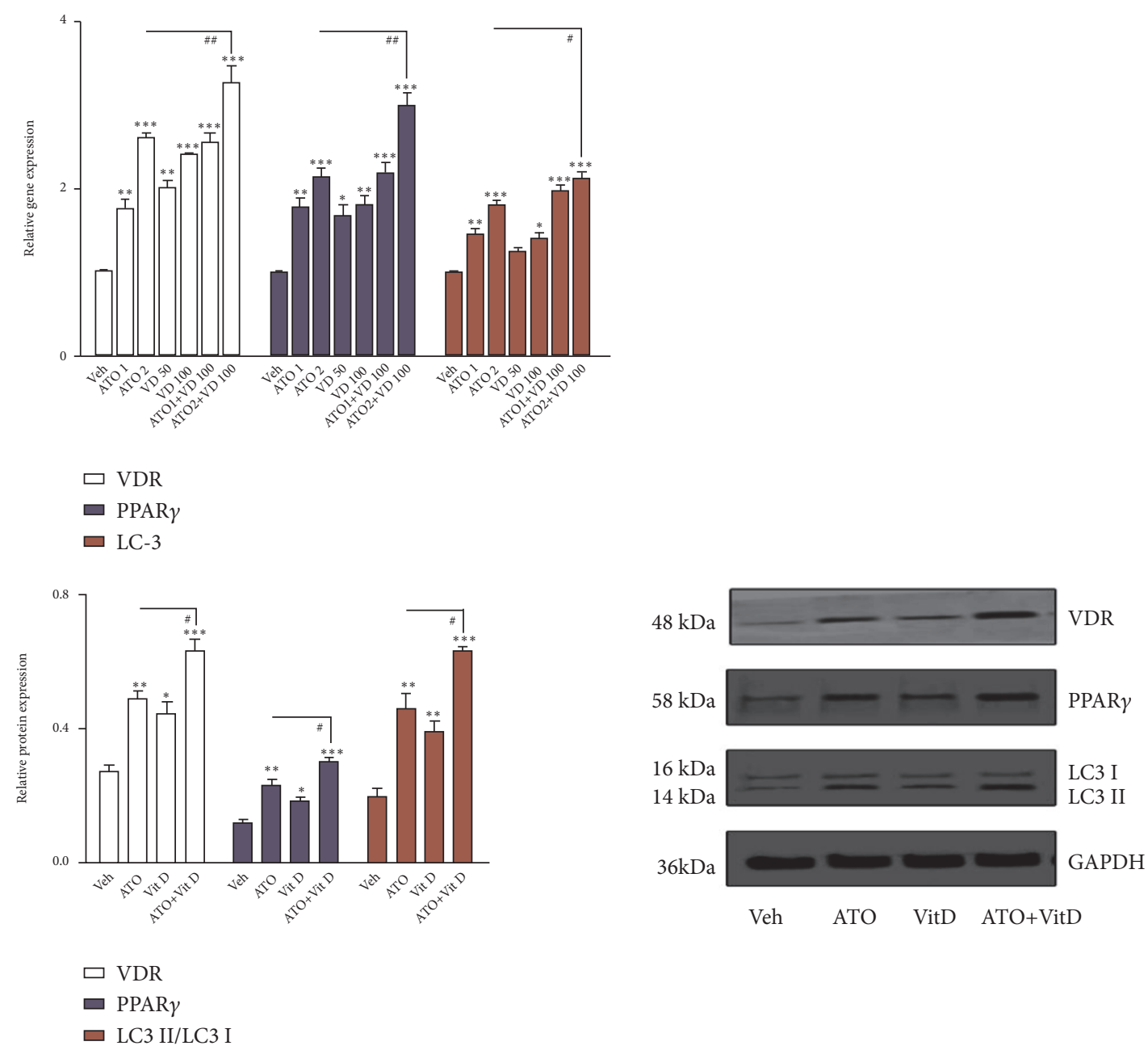

PPAR $\gamma$

LC3 II/LC3 I

(a)

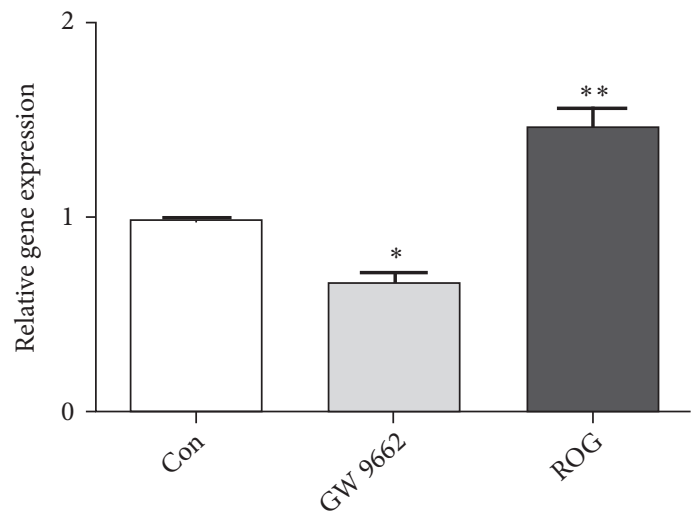

(b)

Figure 3: Combined effect of arsenic trioxide (ATO) and Vitamin D (Vit D) on the Vitamin D receptor (VDR)-PPAR- $\gamma$ autophagy functional module. (a) Synergic upregulation of VDR, PPAR- $\gamma$, and LC-3 in rheumatoid arthritis (RA) fibroblast-like synoviocytes (FLS) after administration of ATO $(2 \mu \mathrm{M})$ and Vit D $(50$ and100 nM) alone or in combination compared with the vehicle $(n=3 ; * p<0.05 ; * * p<0.01$; $* * * p<0.001$ ). (b) Real-time PCR showed a significant decrease in the expression of VDR mRNA in RA FLS after treatment with GW9662, an antagonist of PPAR- $\gamma$. On the other hand, treatment with rosiglitazone (ROG) significantly upregulated VDR mRNA expression $(n=3$, $* p<0.05 ; * * p<0.01$ versus RA FLS treated with the medium alone (control). 


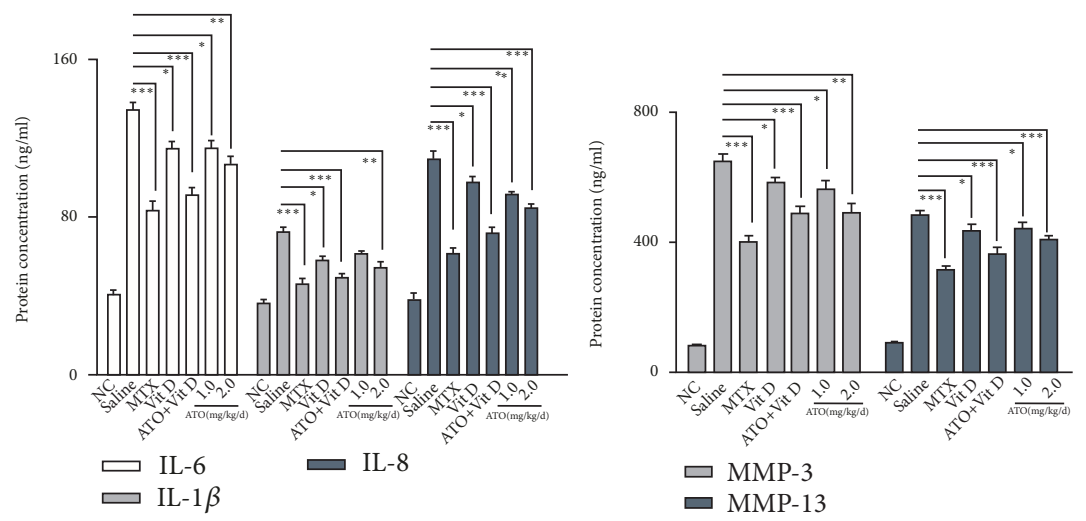

(a)
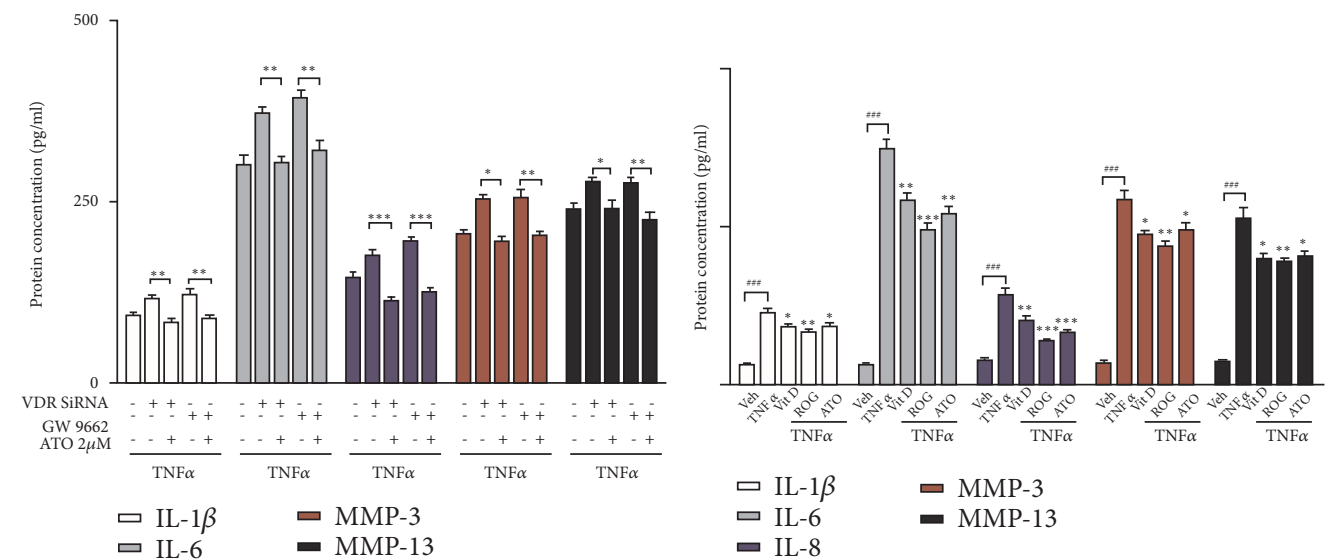

$$
\begin{array}{ll}
\square \text { IL-1 } \beta & \square \text { MMP-3 } \\
\square \text { IL-6 } & \text { DMP-13 } \\
\text { IL-8 } &
\end{array}
$$
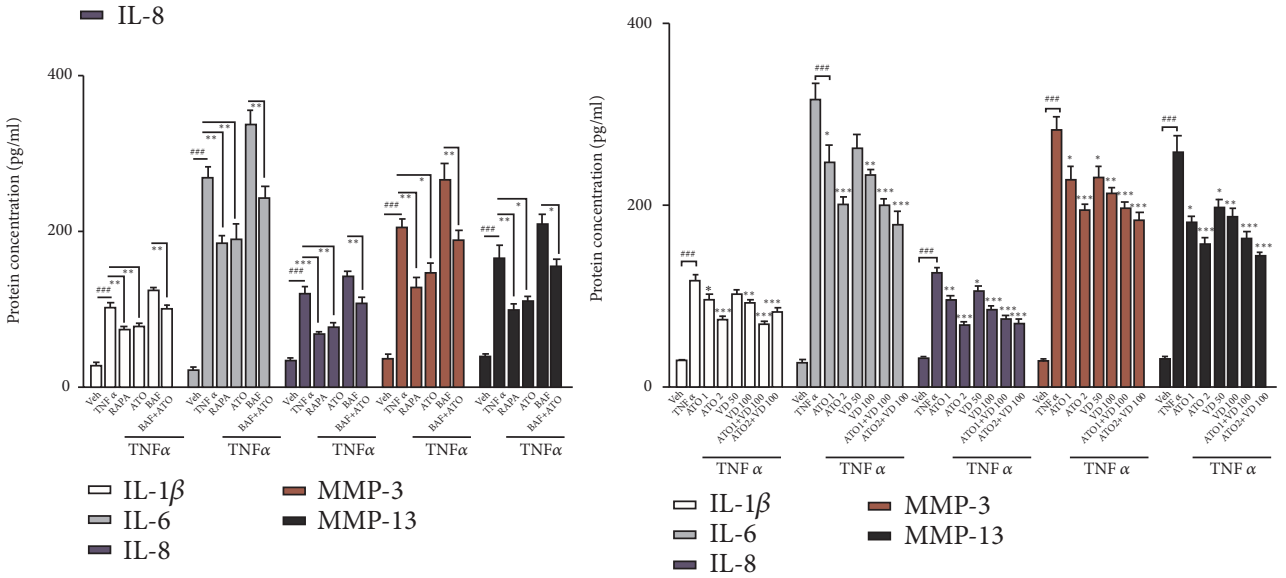

(b)

FIGURE 4: Arsenic trioxide (ATO) suppresses the release of key inflammatory and catabolic cytokines in rheumatoid arthritis (RA). (a) Inflammation module representatives including interleukin-6 (IL-6), IL-1 $\beta$, and IL-8 and catabolism module representatives including matrix metalloproteinase-3 (MMP-3) and MMP-13 decreased in mice serum after the administration of ATO compared with collagen-induced arthritis- (CIA-) saline, whereas they significantly increased in CIA-saline mice compared to normal controls (NC), as shown by enzymelinked immunosorbent assays (ELISA) $(n=6 ; * p<0.05 ; * * p<0.01 ; * * * p<0.001)$. (b) The administration of $2.0 \mu \mathrm{M}$ ATO significantly decreased the expression of inflammation module representatives and catabolism module representatives induced by tumor necrosis factor- $\alpha$ (TNF- $\alpha$ ) $(50 \mathrm{ng} / \mathrm{mL})$ or by silencing the Vitamin D receptor (VDR) by small interfering RNA (siRNA) and inhibiting PPAR- $\gamma$ with GW9662 $(n=3$,

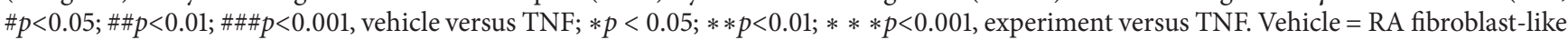
synoviocytes (FLS) with medium; TNF $=$ RA FLS with TNF- $\alpha$ treatment alone). In addition, these cytokines were downregulated by rapamycin and upregulated by BafA1 but this was reversible by ATO $(n=3, * * p<0.05 ; * * p<0.01 ; * * * p<0.001)$. ATO had synergistic effects with Vit D in downregulating the expression of IMRs and CMRs $(n=3, \# p<0.05 ; \# p<0.01 ; \# \# p<0.001$, vehicle versus TNF; $* p<0.05 ; * * p<0.01 ; * * * p$ $<0.001$, experiment versus TNF). 


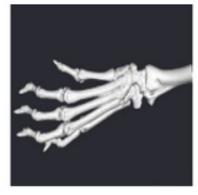

NC

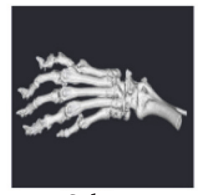

Saline

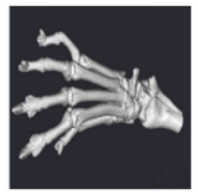

MTX

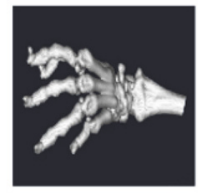

ATO

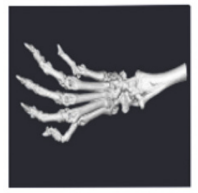

ATO

$2 \mathrm{mg} / \mathrm{kg} / \mathrm{d}$

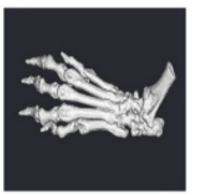

Vit D

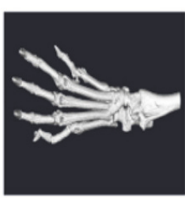

$\mathrm{ATO}+$ Vit D

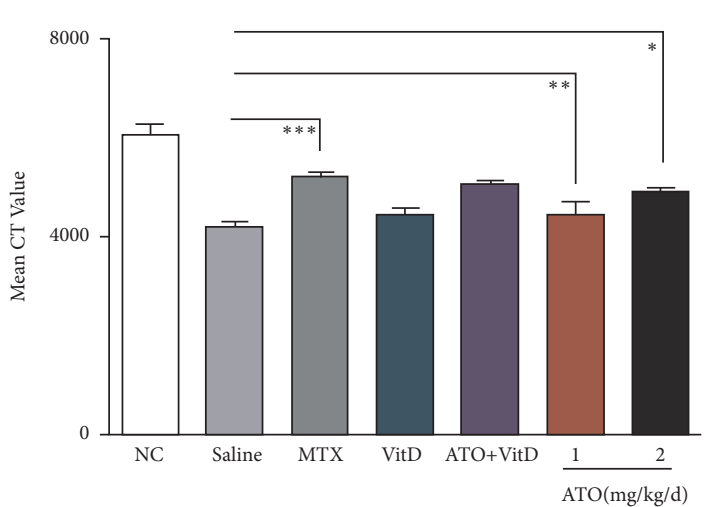

(a)

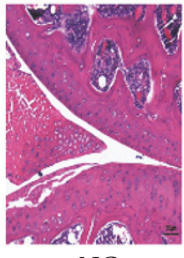

NC

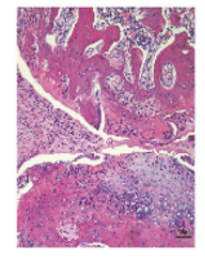

Saline

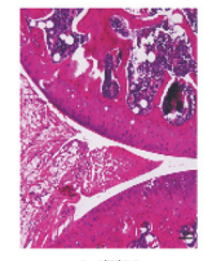

MTX

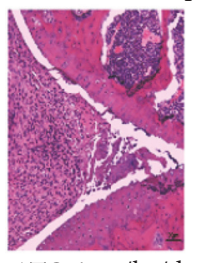

ATO $1 \mathrm{mg} / \mathrm{kg} / \mathrm{d}$

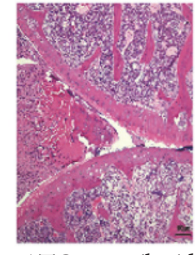

ATO $2 \mathrm{mg} / \mathrm{kg} / \mathrm{d}$

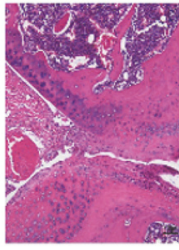

Vit D

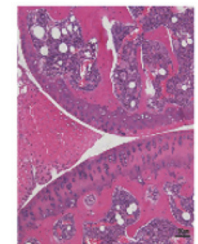

ATO + Vit D

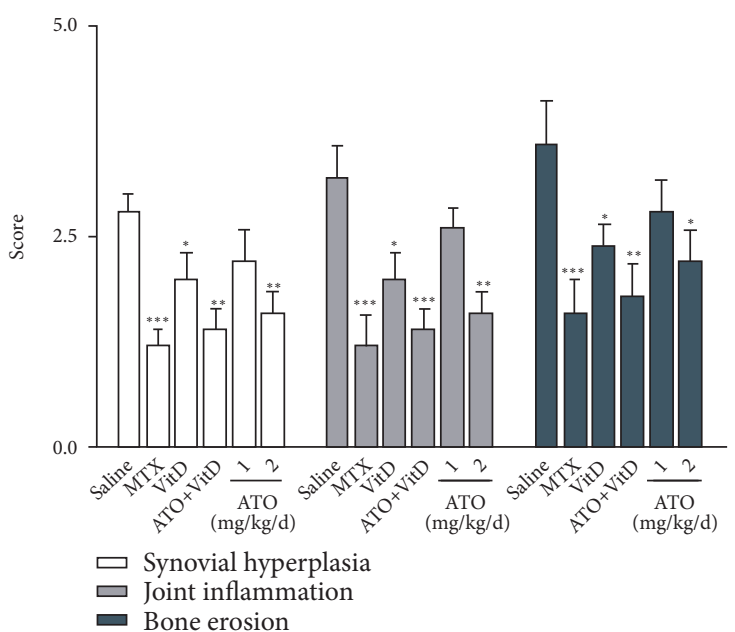

(b)
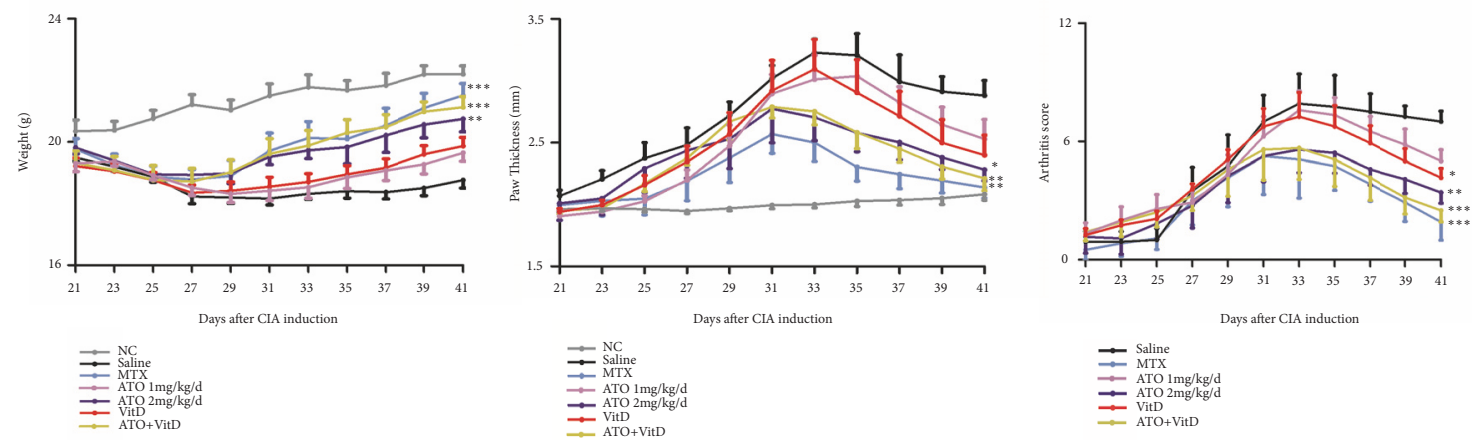

(c)

Figure 5: Arsenic trioxide (ATO) alleviated the symptoms and joint destruction of CIA mice. (a) ATO and Vitamin D (Vit D) alleviate joint destruction and significantly elevated mean CT values in collagen-induced arthritis (CIA) mice compared with normal control (NC) mice $(n=6 ; * p<0.05, * * p<0.01, * * * p<0.001)$. Data are expressed as mean \pm SEM. (b) The severity of arthritis in CIA mice was measured by H\&E staining of knee joints. ATO treatment $(2 \mathrm{mg} / \mathrm{kg} / \mathrm{d})$ and Vit D $(400 \mathrm{ng} / \mathrm{kg} / \mathrm{d})$ significantly reduced the histological scores, including synovial hyperplasia, cartilage and bone erosion, and joint inflammation compared with NC $(n=6 ; * p<0.05, * * p<0.01, * * * p<0.001)$. Magnification $=20 \times$. Bars $=50 \mu \mathrm{m}$. Data are expressed as mean \pm SEM. (c) Collagen-induced arthritis- (CIA-) saline mice (saline) showed a significant decrease in weight and increased paw thickness and arthritis scores compared with the normal control (NC) group. Arsenic trioxide (ATO) at $2.0 \mathrm{mg} / \mathrm{kg} /$ day, Vitamin D (Vit D), and methotrexate (MTX) $(\mathrm{n}=6)$ significantly increased bodyweight and decreased paw thickness and arthritis scores $(\mathrm{n}=6, * \mathrm{p}<0.05, * * \mathrm{p}<0.01, * * * \mathrm{p}<0.001$, treatment versus saline). Data are expressed as means \pm SEM. 
mean CT values of hind paws compared with CIA-saline mice, as did MTX (2 mg/kg/w) (Figure 5(a); $n=6, p<0.01)$.

3.4. ATO Inhibits the TNF- $\alpha$-Induced Inflammation Module Representative and Catabolism Module Representative Release by Regulating the VDR-PPAR- $\gamma$ Autophagy Functional Module. Interestingly, ATO (1 mg/kg/d) decreased MMP-13 expression, but key inflammation biomarkers such as IL-6, IL- $1 \beta$, and IL- 8 and catabolism factor module representatives including MMP-3 and MMP-13 were significantly suppressed by ATO $(2 \mathrm{mg} / \mathrm{kg} / \mathrm{d})$ (Figure $4(\mathrm{a}), p<0.01)$ but were significantly upregulated in CIA-saline mice compared with the normal control mice, as shown by ELISA (Figure 4(a), $p<0.01)$. Vit D $(400 \mathrm{ng} / \mathrm{kg} / \mathrm{d})$ alone significantly decreased these cytokines and may significantly enhance the effect of ATO when used in combination (Figure 4(a), $p<0.05$ ). Therefore, ATO and Vit D downregulated inflammation factors and catabolism factors in CIA mouse serum in vivo.

Furthermore, TNF- $\alpha$ treatment $(50 \mathrm{ng} / \mathrm{mL})$ significantly induced the inflammation factors and catabolism factors in RA FLS. Stimulation of the VDR-PPAR- $\gamma$ functional module by its agonist Vit $\mathrm{D}$ and rosiglitazone $(50 \mu \mathrm{mol} / \mathrm{L})$ decreased cytokine release, as did ATO with or without Vit D. In contrast, silencing VDR by siRNA and inhibiting PPAR- $\gamma$ with GW9662 $(10 \mu \mathrm{mol} / \mathrm{L})$ increased the secretion of inflammatory and catabolic factors (Figure $4(\mathrm{~b}), p<0.05$ ); this was reversed by ATO. Furthermore, inflammation and catabolism factors were downregulated by stimulating autophagy with rapamycin $(100 \mathrm{nmol} / \mathrm{L})$. Consistently, the autophagy blocker BafAl induced cytokine release but ATO reversed this effect (Figure 4(b), $p<0.05)$. Therefore, ATO inhibited the release of TNF- $\alpha$-induced inflammation factors and catabolism factors in RA FLS by regulating the VDR-PPAR- $\gamma$ autophagy module.

\section{Discussion}

Autophagy is a highly conserved biological process in eukaryotic cells. Some autophagy-associated genes are closely related to RA [36].

Firstly, we explored the roles of VDR and PPAR- $\gamma$ during autophagy in RA FLS. To the best of our knowledge, this is the first study reporting that the expressions of VDR, PPAR- $\gamma$, and LC-3 are significantly upregulated, and mTOR is significantly downregulated in RA FLS. Our results showed that p62 in RA FLS was significantly upregulated, indicating autophagic flux obstruction. Since impaired autophagic flux may be involved in a variety of diseases [37], we concluded that defective autophagic flux, rather than other factors causing functional loss of autophagy, leads to RA.

Indeed, PPAR- $\gamma$ and VDR are interconnected and modulate the expression of genes in similar ways as a functional module $[38,39]$. In order to further clarify the relationship between PPAR- $\gamma$ and VDR in RA FLS, we applied rosiglitazone to excite PPAR- $\gamma$ plaques in RA FLS and found that VDR expression was also elevated, suggesting that PPAR $-\gamma$ may have a positive feedback effect on VDR.
Anti-TNF biological agents have been proven to be effective in the treatment of RA; however, around $30 \%$ of the patients respond poorly or not at all to the biologics. In addition, the treatment is limited by preexisting malignancy and inflammation and further impose an economic burden on patients because of the high costs. ATO has attracted global attention as one of several highly promising effective anticancer drugs. To our knowledge, this is the first report to demonstrate that ATO may rescue impaired autophagic flux beyond its role in activating the VDR-PPAR- $\gamma$ autophagy functional module, consequently inhibiting the inflammatory response and joint destruction.

Previously, we and others reported that ATO may relieve the clinical symptoms of patients with leukemia and other rheumatic diseases [27, 40,41]. Although we observed no significant effect of ATO on cell proliferation and no toxic effect on CIA mice, several adverse effects have been reported in patients such as liver injury and carcinogenesis [41], which limit the application of ATO in clinical settings. Solution could be sought regarding local drug delivery, drug combinations [42], or chemical modifications [43]. For the first time, we provided evidence that ATO showed a synergistic effect in combination with Vit $\mathrm{D}$ both in vivo and in vitro. Since Vit D is safe and easily available, the combination of the two drugs may reduce the dosage of ATO and mitigate its side effects.

\section{Conclusion}

In closing, VDR, PPAR- $\gamma$, LC-3, and p62 form a functional module, which is obviously upregulated in RA FLS and CIA mice synovial fibroblasts, but with impaired autophagic flux, as demonstrated by the upregulation of $\mathrm{p} 62$.

Although the exact mechanisms are still poorly understood, ATO may enhance the VDR-PPAR- $\gamma$ autophagy functional module and rescue impaired autophagic flux both in vivo and in vitro in RA and consequently inhibit the expression of inflammatory and catabolic factors that participate in joint destruction (Figure 6). Furthermore, we provided evidence that low-dose ATO showed a better effect in combination with Vit D in ameliorating RA symptoms, suggesting novel promising protocols for RA and cancer therapy.

\section{Data Availability}

The data used to support the findings of this study are available from the corresponding author upon request.

\section{Conflicts of Interest}

The authors declare that they have no conflicts of interest.

\section{Authors' Contributions}

Weiyan Wang, Chun Ling Li, and Yue Zhang contributed equally to this work. 


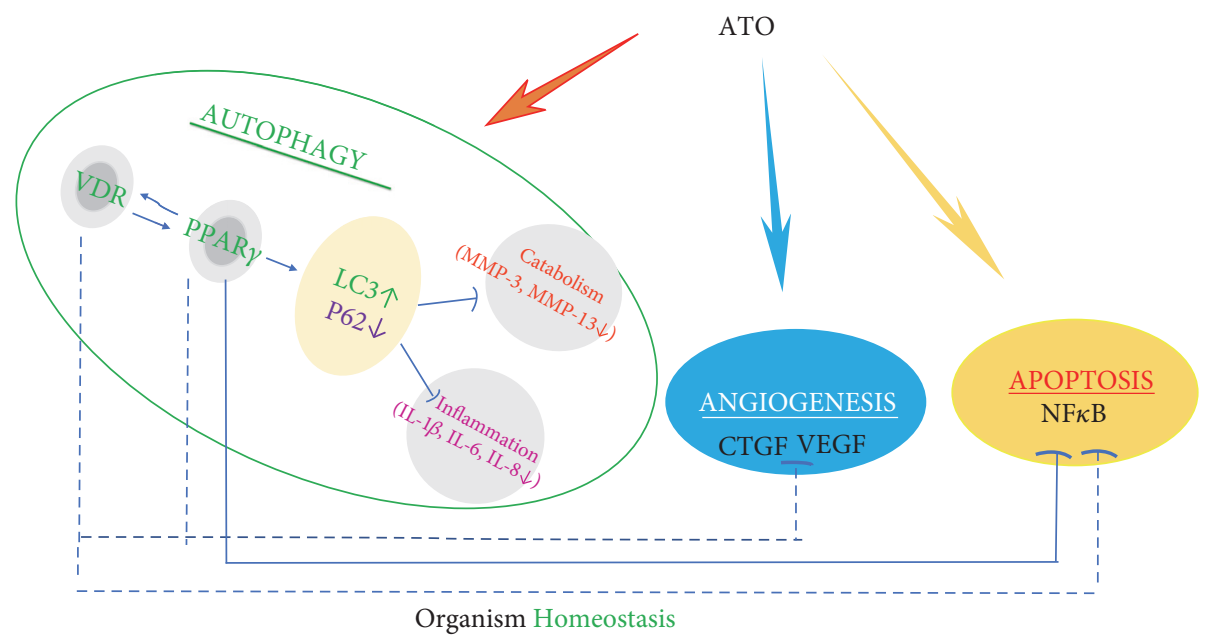

FiguRE 6: Regulation effect of ATO on VDR-PPAR- $\gamma$ functional module. The Vitamin D receptor (VDR) and PPAR- $\gamma$ interplay with each other and form a functional module. ATO rescued defective autophagy by regulating this functional module in synovial fibroblasts, thus inhibiting the expression of inflammatory and catabolic factors. Serving as a regulatory mechanism, autophagy has complex interrelationships with other physiological processes including angiogenesis and apoptosis, which can be regulated by ATO. The solid lines indicate our original data or results from our study that have been corroborated by other labs; dotted lines indicate that research is still ongoing.

\section{Acknowledgments}

This work is supported by grants from the National Natural Science Foundation of China to Zhiyi Zhang (NSFC 81771749) and Yue Zhang (NSFC 81771748).

\section{References}

[1] J. S. Smolen, D. Aletaha, and I. B. McInnes, "Rheumatoid arthritis," The Lancet, vol. 388, no. 10055, pp. 2023-2038, 2016.

[2] J. S. Rockel and M. Kapoor, "Autophagy: controlling cell fate in rheumatic diseases," Nature Reviews Rheumatology, vol. 12, no. 9, pp. 517-531, 2016.

[3] A. M. Choi, S. W. Ryter, and B. Levine, "Autophagy in human health and disease," The New England Journal of Medicine, vol. 368, no. 7, pp. 651-662, 2013.

[4] A. Doria, M. Gatto, and L. Punzi, "Autophagy in human health and disease," The New England Journal of Medicine, vol. 368, no. 19, pp. 1845-1846, 2013.

[5] B. Levine and G. Kroemer, "Biological functions of autophagy genes: a disease perspective," Cell, vol. 176, pp. 11-42, 2019.

[6] F. Vasheghani, Y. Zhang, Y.-H. Li et al., "PPARgamma deficiency results in severe, accelerated osteoarthritis associated with aberrant mTOR signalling in the articular cartilage," Annals of the Rheumatic Diseases, vol. 74, no. 3, pp. 569-578, 2015.

[7] D. E. Harrison, R. Strong, Z. D. Sharp et al., "Rapamycin fed late in life extends lifespan in genetically heterogeneous mice," Nature, vol. 460, no. 7253, pp. 392-395, 2009.

[8] T. Vellai, K. Takacs-Vellai, Y. Zhang, A. L. Kovacs, L. Orosz, and F. Müller, "Genetics: influence of TOR kinase on lifespan in C. elegans," Nature, vol. 426, no. 6967, pp. 620-621, 2003.

[9] Y. Zhang, F. Vasheghani, Y.-H. Li et al., "Cartilage-specific deletion of mTOR upregulates autophagy and protects mice from osteoarthritis," Annals of the Rheumatic Diseases, vol. 74, no. 7, pp. 1432-1440, 2015.
[10] Y. Matsuzawa-Ishimoto, S. Hwang, and K. Cadwell, "Autophagy and Inflammation," Annual Review of Immunology, vol. 36, pp. 73-101, 2018.

[11] Y. Okada, D. Wu, G. Trynka, T. Raj et al., "Genetics of rheumatoid arthritis contributes to biology and drug discovery," Nature, vol. 506, pp. 376-381, 2014.

[12] S. V. Ramagopalan, A. Heger, A. J. Berlanga et al., "A ChIPseq defined genome-wide map of vitamin $\mathrm{D}$ receptor binding: associations with disease and evolution," Genome Research, vol. 20, no. 10, pp. 1352-1360, 2010.

[13] Y. Zhang, "Emerging vitamin D receptor-centered patterns of genetic overlap across some autoimmune diseases and associated cancers," Journal of Genetic Syndromes \& Gene Therapy, vol. 04, no. 11, Article ID 1000e1123, 2013.

[14] D. Hochbaum, Y. Zhang, C. Stuckenholz et al., "DAF-12 regulates a connected network of genes to ensure robust developmental decisions," PLoS Genetics, vol. 7, no. 7, Article ID e1002179, 2011.

[15] F. Alimirah, X. Peng, L. Yuan et al., "Crosstalk between the peroxisome proliferator-activated receptor gamma (PPAR $\gamma)$ and the vitamin D receptor (VDR) in human breast cancer cells: PPAR $\gamma$ binds to VDR and inhibits $1 \alpha, 25$-dihydroxyvitamin D3 mediated transactivation," Experimental Cell Research, vol. 318, no. 19, pp. 2490-2497, 2012.

[16] T. Yao, X. Ying, Y. Zhao et al., "Vitamin D receptor activation protects against myocardial reperfusion injury through inhibition of apoptosis and modulation of autophagy," Antioxidants \& Redox Signaling, vol. 22, no. 8, pp. 633-650, 2015.

[17] L. Wang, Y. Yin, G. Hou, J. Kang, and Q. Wang, "Peroxisome proliferator-activated receptor $(\operatorname{PPAR} \gamma)$ plays a protective role in cigarette smoking-induced inflammation via AMP-activated protein kinase (AMPK) signaling," Medical Science Monitor, vol. 24, pp. 5168-5177, 2018.

[18] L. F. da Rocha Junior, M. J. Rêgo, and M. B. Cavalcanti, "Synthesis of a novel thiazolidinedione and evaluation of its modulatory effect on IFN- $\gamma$, IL-6, IL-17A, and IL-22 production 
in PBMCs from rheumatoid arthritis Patients," BioMed Research International, vol. 2013, Article ID 926060, 8 pages, 2013.

[19] V. Costa, D. Foti, F. Paonessa et al., "The insulin receptor: a new anticancer target for peroxisome proliferator-activated receptor-gamma (PPARgamma) and thiazolidinedionePPARgamma agonists," Endocrine-Related Cancer, vol. 15, no. 1, pp. 325-335, 2008.

[20] M. Koufany, D. Chappard, P. Netter et al., "The peroxisome proliferator-activated receptor gamma agonist pioglitazone preserves bone microarchitecture in experimental arthritis by reducing the interleukin-17-dependent osteoclastogenic pathway," Arthritis \& Rheumatism, vol. 65, no. 12, pp. 3084-3095, 2013.

[21] L. E. Tavera-Mendoza, T. Westerling, E. Libby et al., "Vitamin $\mathrm{D}$ receptor regulates autophagy in the normal mammary gland and in luminal breast cancer cells," Proceedings of the National Acadamy of Sciences of the United States of America, vol. 114, no. 11, pp. E2186-E2194, 2017.

[22] L. M. Das, A. M. Binko, Z. P. Traylor, H. Peng, and K. Q. Lu, "Vitamin D improves sunburns by increasing autophagy in M2 macrophages," Autophagy, vol. 15, no. 5, pp. 813-826, 2019.

[23] J. Zhong, W. Gong, J. Chen et al., "Micheliolide alleviates hepatic steatosis in $\mathrm{db} / \mathrm{db}$ mice by inhibiting inflammation and promoting autophagy via PPAR- $\gamma$-mediated NF- $\mathrm{KB}$ and AMPK/mTOR signaling," International Immunopharmacology, vol. 59, pp. 197-208, 2018.

[24] I. Bellantuono, "Find drugs that delay many diseases of old age," Nature, vol. 554, no. 7692, pp. 293-295, 2018.

[25] Z. Chen and S.-J. Chen, "Poisoning the Devil," Cell, vol. 168, no. 4, pp. 556-560, 2017.

[26] H. Zhang, L. Yang, J. Ling et al., "Systematic identification of arsenic-binding proteins reveals that hexokinase- 2 is inhibited by arsenic," Proceedings of the National Acadamy of Sciences of the United States of America, vol. 112, no. 49, pp. 15084-15089, 2015.

[27] Y. Mei, Y. Zheng, H. Wang et al., "Arsenic trioxide induces apoptosis of fibroblast-like synoviocytes and represents antiarthritis effect in experimental model of rheumatoid arthritis," The Journal of Rheumatology, vol. 38, no. 1, pp. 36-43, 2011.

[28] J. Zhang, C. Li, Y. Zheng, Z. Lin, Y. Zhang, and Z. Zhang, "Inhibition of angiogenesis by arsenic trioxide via TSP-1-TGF$\beta 1$-CTGF-VEGF functional module in rheumatoid arthritis," Oncotarget, vol. 8, no. 43, pp. 73529-73546, 2017.

[29] Y. Zhao, G. Wen, Z. Qiao et al., "Effects of tetra-arsenic tetrasulfide on BXSB lupus-prone mice: A pilot study," Lupus, vol. 22, no. 5, pp. 469-476, 2013.

[30] T. Li, R. Ma, Y. Zhang et al., "Arsenic trioxide promoting ETosis in acute promyelocytic leukemia through mTOR-regulated autophagy," Cell Death \& Disease, vol. 9, no. 2, pp. 1-14, 2018.

[31] X. Wang, Y. Zhang, Z. Han, and K. He, "Malignancy of Cancers and synthetic lethal interactions associated with mutations of cancer driver genes," Medicine, vol. 95, no. 8, p. e2697, 2016.

[32] K. Tanaka, M. Hashizume, M. Mihara, H. Yoshida, M. Suzuki, and Y. Matsumoto, "Anti-interleukin-6 receptor antibody prevents systemic bone mass loss via reducing the number of osteoclast precursors in bone marrow in a collagen-induced arthritis model," Clinical \& Experimental Immunology, vol. 175, no. 2, pp. 172-180, 2014.

[33] X. Luo, Y. Chen, G. Lv et al., "Adenovirus-mediated small interfering RNA targeting TAK1 ameliorates joint inflammation with collagen-induced arthritis in mice," Inflammation, vol. 40, no. 3, pp. 894-903, 2017.
[34] R. S. Peres, G. B. Santos, N. T. Cecilio et al., "Lapachol, a compound targeting pyrimidine metabolism, ameliorates experimental autoimmune arthritis," Arthritis Research \& Therapy, vol. 19, no. 1, pp. 47-59, 2017.

[35] G. Lu, J. Liao, G. Yang, K. R. Reuhl, X. Hao, and C. S. Yang, "Inhibition of adenoma progression to adenocarcinoma in a 4-(methylnitrosamino)-1-(3-pyridyl)-1-butanone-induced lung tumorigenesis model in A/J mice by tea polyphenols and caffeine," Cancer Research, vol. 66, no. 23, pp. 11494-11501, 2006.

[36] A. Chatzikyriakidou, P. V. Voulgari, and A. A. Drosos, "Lack of association of the autophagy-related gene polymorphism ATG16L1 rs2241880 in RA predisposition," Rheumatology International, vol. 34, no. 4, pp. 477-479, 2014.

[37] D. J. Klionsky, K. Abdelmohsen, A. Abe, M. J. Abedin et al., "Guidelines for the use and interpretation of assays for monitoring autophagy," Autophagy, vol. 12, pp. 1-222, 2016.

[38] K. K. Deeb, D. L. Trump, and C. S. Johnson, "Vitamin D signalling pathways in cancer: potential for anticancer therapeutics," Nature Reviews Cancer, vol. 7, no. 9, pp. 684-700, 2007.

[39] K. W. Nettles, "Insights into PPAR gamma from structures with endogenous and covalently bound ligands," Nature Structural \& Molecular Biology, vol. 15, no. 9, pp. 893-895, 2008.

[40] F. Ge, Y. Zhang, F. Cao et al., "Arsenic trioxide-based therapy is suitable for patients with psoriasis-associated acute promyelocytic leukemia - A retrospective clinical study," International Journal of Hematology, vol. 21, no. 5, pp. 287-294, 2016.

[41] T.-D. Zhang, G.-Q. Chen, Z.-G. Wang, Z.-Y. Wang, S.-J. Chen, and Z. Chen, "Arsenic trioxide, a therapeutic agent for APL," Oncogene, vol. 20, no. 49, pp. 7146-7153, 2001.

[42] W. Zhang, Y. Liu, M. Ge et al., "Protective effect of resveratrol on arsenic trioxide-induced nephrotoxicity in rats," Nutrition Research and Practice, vol. 8, no. 2, pp. 220-226, 2014.

[43] R. W. Ahn, S. L. Barrett, M. R. Raja et al., "Nano-encapsulation of arsenic trioxide enhances efficacy against murine lymphoma model while minimizing its impact on ovarian reserve in vitro and in vivo," PLoS ONE, vol. 8, no. 3, Article ID e58491, 2013. 


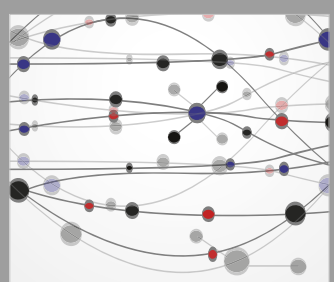

The Scientific World Journal
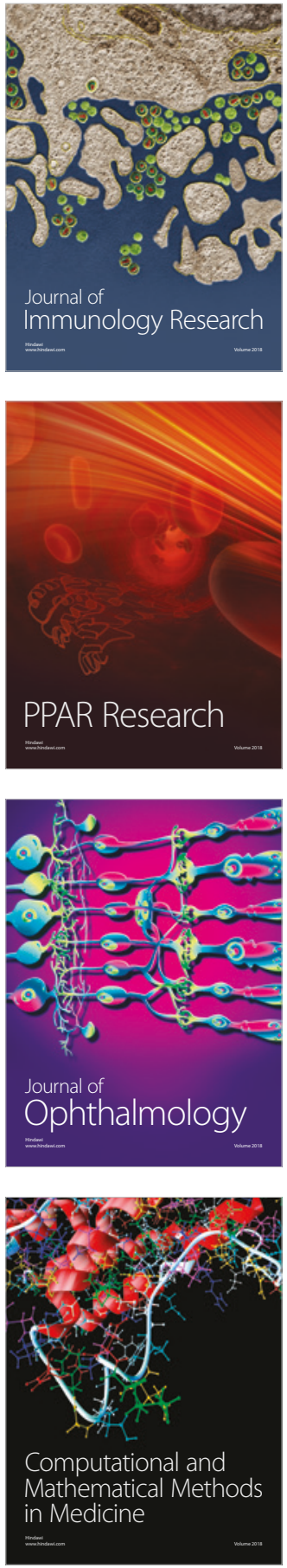

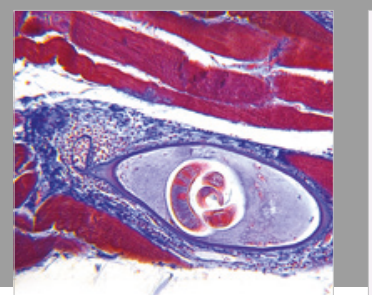

Gastroenterology Research and Practice

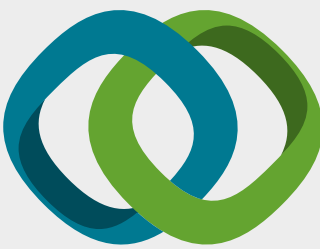

\section{Hindawi}

Submit your manuscripts at

www.hindawi.com
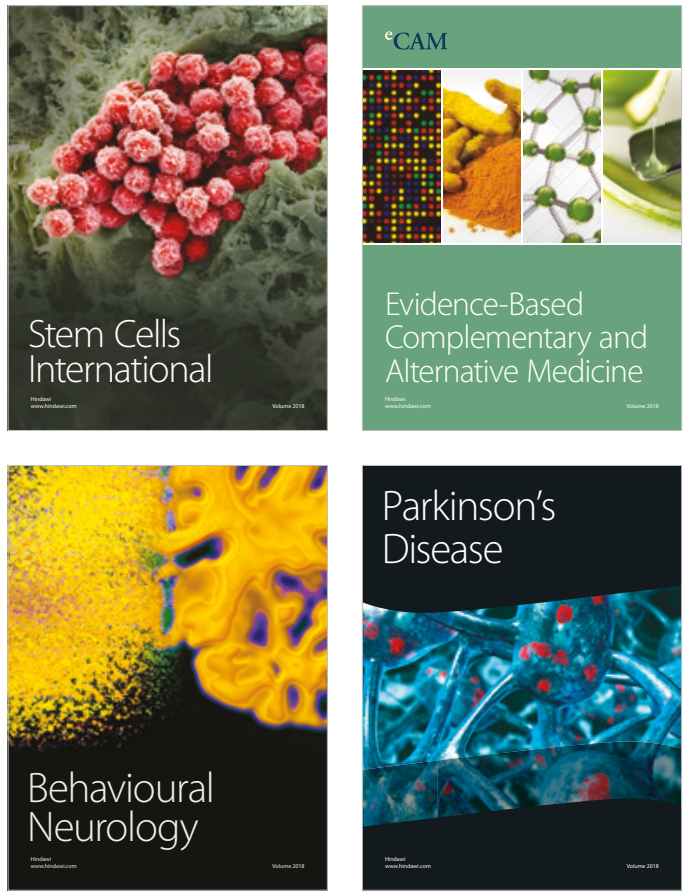

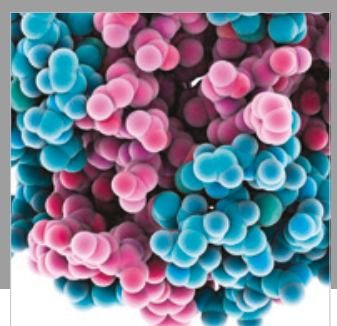

ournal of

Diabetes Research

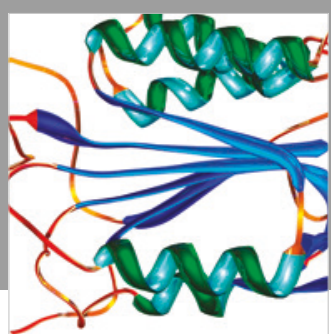

Disease Markers
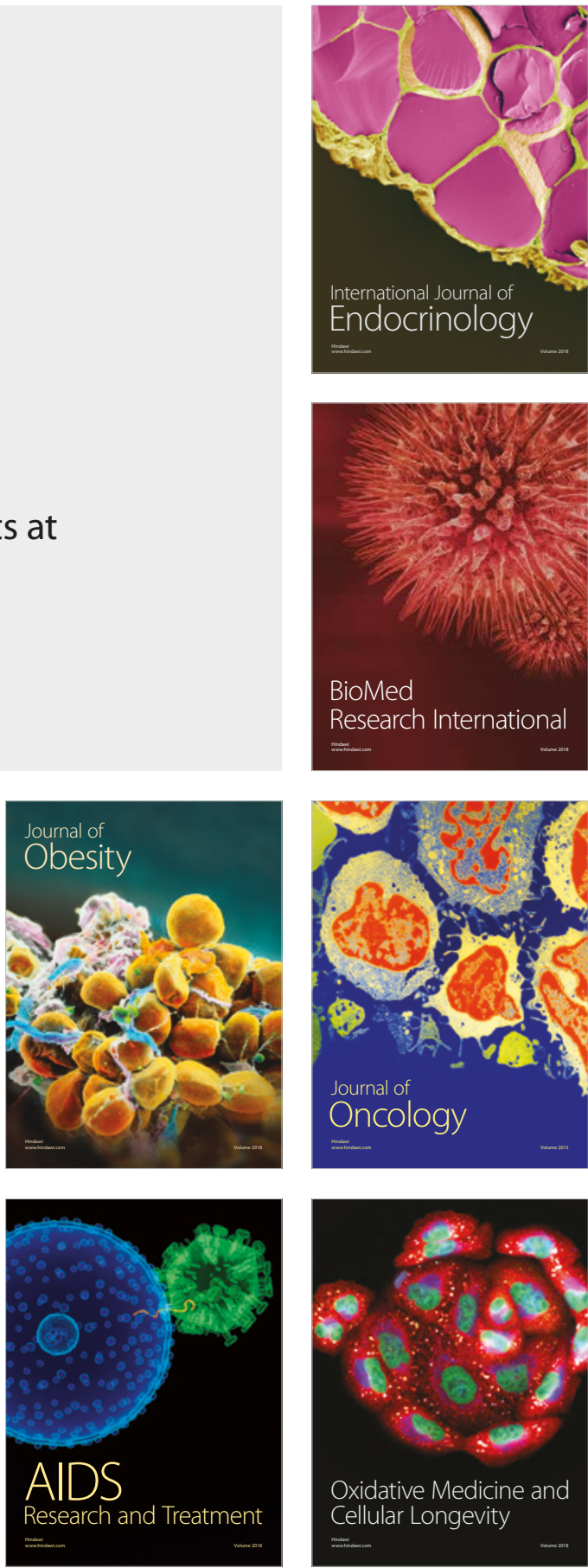